Research Paper

\title{
GSPE reduces lead-induced oxidative stress by activating the Nrf2 pathway and suppressing miR153 and GSK-3 $\beta$ in rat kidney
}

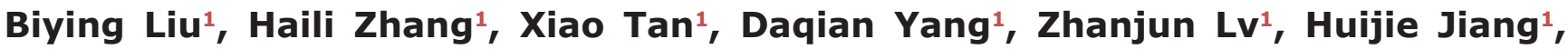 \\ Jingjing Lu ${ }^{1}$, Ruiqi Baiyun ${ }^{1}$ and Zhigang Zhang ${ }^{1}$ \\ ${ }^{1}$ College of Veterinary Medicine, Northeast Agricultural University, Harbin 150030, China \\ Correspondence to: Zhigang Zhang, email: zhangzhigang@neau.edu.cn \\ Keywords: grape seed procyanidin extract, kidney injury, oxidative stress, Nrf2, nephroprotective effect
}

Received: September 24, $2016 \quad$ Accepted: January 16, $2017 \quad$ Published: February 02, 2017

Copyright: Liu et al. This is an open-access article distributed under the terms of the Creative Commons Attribution License 3.0 (CC BY 3.0), which permits unrestricted use, distribution, and reproduction in any medium, provided the original author and source are credited.

\section{ABSTRACT}

Lead $(\mathrm{Pb})$ is a global environmental health hazard that leads to nephrotoxicity. However, the effective treatment of $\mathbf{P b}$-induced nephrotoxicity remains elusive. Grape seed procyanidin extract (GSPE) has beneficial properties for multiple biological functions. Therefore, the present study investigated whether GSPE reduced Pbinduced nephrotoxicity as well as the protective mechanism of GSPE in a wellestablished 35-day $\mathrm{Pb}$ induced nephrotoxicity rat model. The results showed that GSPE normalized Pb-induced oxidative stress, histological damage, inflammatory,

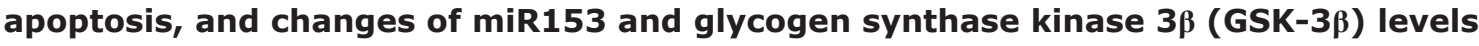
in rat kidney. Moreover, GSPE enhanced the induction of phase II detoxifying enzymes (heme oxygenase-1 and NAD(P)H quinone oxidoreductase 1) by increasing nuclear factor-erythroid-2-related factor 2 ( Nrf2) expression. This study identifies for the first time that $\mathbf{P b}$-induced oxidative stress in rat kidney is attenuated by GSPE treatment

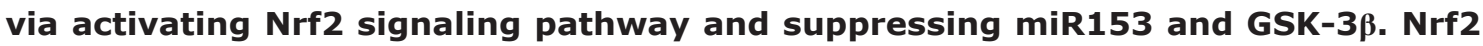
signaling provides a new therapeutic target for renal injury induced by $\mathbf{P b}$, and GSPE could be a potential natural agent to protect against $\mathbf{P b}$-induced nephrotoxicity.

\section{INTRODUCTION}

Lead $(\mathrm{Pb})$ is a global environmental health hazard that poses a substantial risk to humans and animals. $\mathrm{Pb}$ exposure affects the nervous, immune, renal, skeletal, and hematopoietic systems [1]. Furthermore, $\mathrm{Pb}$ easily penetrates through biological membranes and exhibits accumulation patterns in tissues [2]. Kidney is one of the main excretion pathways of $\mathrm{Pb}$ in organisms and is a target organ for $\mathrm{Pb}$ cytotoxicity [3]. $\mathrm{Pb}$ is often released in the environment from natural and anthropogenic sources. Therefore, nephrotoxicity of $\mathrm{Pb}$ is a significant public health concern.

At present, the mechanism(s) underlying $\mathrm{Pb}$-induced nephrotoxicity development remain poorly understood. Evidence from animal studies suggests an important factor of lipid peroxidation and degradation of phospholipids in kidney damage is caused by $\mathrm{Pb}$ toxicity, which leads to a loss of membrane integrity [4]. Besides, when cells are overwhelmed by oxidative stress, genes involved in cell death signaling are activated to induce apoptosis or necrosis to remove irreversibly damaged cells [5]. Therefore, an increase in the level of apoptosis may underline the pathogenesis of kidney injury. Furthermore, oxidative stress and inflammation, which are tightly linked, are characteristic features of kidney disease [6]. Nuclear factor- $\kappa \mathrm{B}(\mathrm{NF}-\kappa \mathrm{B})$ activity is inducible in all cell types and regulates many genes involved in inflammatory responses [7]. NF- $\kappa \mathrm{B}$ can be stimulated by $\mathrm{Pb}$ and is a major factor in pathological conditions of the kidney [8]. Thus, attenuated oxidative stress may serve as a potential mechanism for renal toxic injury and disease induced by $\mathrm{Pb}$.

Glycogen synthase kinase $3 \beta(\mathrm{GSK}-3 \beta)$ is a redox sensitive signaling molecule that plays a pivotal role in a multitude of signaling pathways, including NF- $\kappa B$, nuclear factor-erythroid-2-related factor 2 (Nrf2), and others. Remarkably, Nrf2 activates antioxidant enzymes and inhibits oxidative stress induced damage [9]. The self-protective antioxidant effects of $\mathrm{Nrf} 2$ are controlled by GSK-3 $\beta$, which 
promotes the nuclear export and degradation of Nrf2 upon oxidative stress, culminating in switching off the Nrf2 antioxidant response [10]. The switching on and off of $\mathrm{Nrf} 2$ protects cells against free radical damage, apoptosis, and promotes cell survival [11]. Interestingly, a recent study showed that the enforced expression of miR153 elicited a post-transcriptional repression of Nrf2 [12]. However, it is still unclear whether Nrf2 plays a role in nephrotoxicity of $\mathrm{Pb}$.

Currently, $\mathrm{Pb}$ poisoning is commonly treated by chelating agents such as disodium edetate calcium and sodium dimercaptosuccinate in clinics. $\mathrm{Pb}$ forms an insoluble complex with chelating agents to allow its removal from the $\mathrm{Pb}$-burdened tissue, but these chelating agents are incapable of removing metal from intracellular sites and may cause a redistribution of the toxic metal, essential metal loss, and liver or renal dysfunction [13]. Therefore, it is important to develop safe and effective treatments for $\mathrm{Pb}$ poisoning.

Grape seed procyanidin extract (GSPE) belongs to a larger group of polyphenolic compounds and contains oligomers and polymers of monomeric flavonoids [14]. In addition to antioxidant, GSPE has antiviral, antibacterial, anti-inflammatory, and antiapoptotic effects $[15,16]$. Remarkably, GSPE also has unique properties that prevent kidney injury induced by colistin [17], cisplatin [18], and cyclosporine A [19]. The specific role of GSPE in Pb-induced nephrotoxicity is unknown.
We hypothesized that GSPE could suppress nephrotoxicity of $\mathrm{Pb}$. To investigate this, we measured the regulatory effects of GSPE on the Nrf2 signaling pathway induced by $\mathrm{Pb}$ and the mechanisms involved in the GSPEmediated protection against $\mathrm{Pb}$-induced nephrotoxicity.

\section{RESULTS}

\section{GSPE attenuates $\mathrm{Pb}$-induced renal damage}

Histopathological change is a direct indication of renal injury. Hematoxylin and eosin stained renal tissues showed normal kidney tubules and corpuscles in the control group (Figure 1A) and GSPE group samples (Figure 1D). In contrast, $\mathrm{Pb}$-induced histopathological changes were observed in the renal tissues including the destruction of tubular structures, necrosis and disorganization, inflammatory cell infiltration, vacuolar degeneration, and hyperemia of the renal interstitium (Figure 1B). However, coadministration of GSPE significantly diminished $\mathrm{Pb}$-induced epithelial atrophy, necrosis, and hyperemia (Figure 1C). We measured the renalorgan index (Figure 1E), and GSPE significantly $(\mathrm{P}<0.05)$ restored kidney weight when compared with rats treated with $\mathrm{Pb}$ alone. Results in the GSPE alone group did not differ significantly from the normal control group.

Creatinine (CREA) (Figure 1F) and blood urea nitrogen (BUN) (Figure 1G) levels were significantly
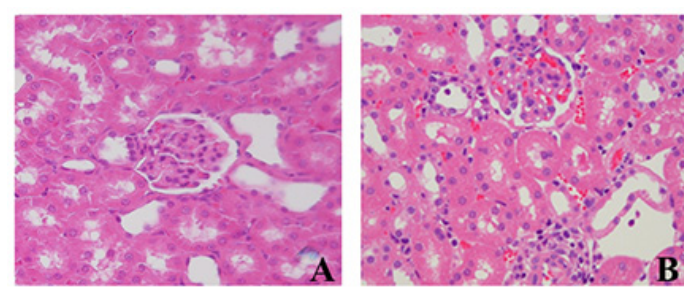

$\mathbf{E}$
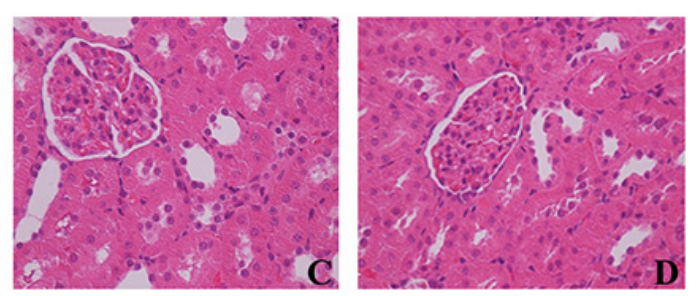

$\mathbf{F}$

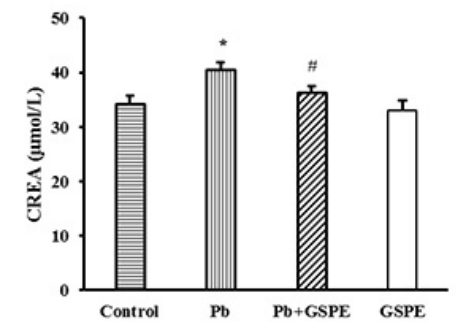

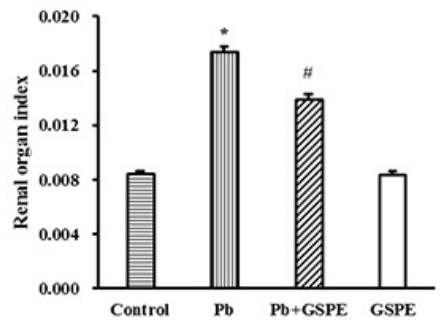

G

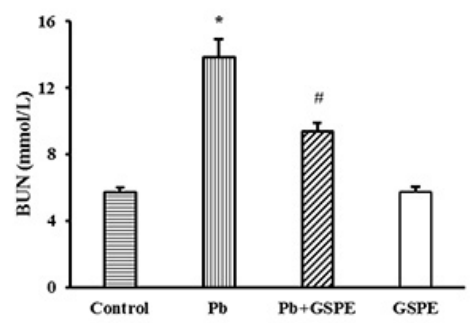

Figure 1: The protective effect of GSPE on Pb-induced renal damage. Histopathological changes in renal tissues: Paraffin sections of kidney tissues from A. control, B. Pb-treated, C. Pb + GSPE, and D. GSPE were stained with hematoxylin and eosin $(\times 400)$. E. The organ index of the kidney in rats. F. CREA level of kidney in rats. G. BUN level of kidney in rats. Data are expressed as mean \pm $\mathrm{SEM}, \mathrm{n}=10$. $^{*}$ Significantly different $(\mathrm{P}<0.05)$ from control group, and ${ }^{*}$ significantly different $(\mathrm{P}<0.05)$ from $\mathrm{Pb}$-treated group. 
higher in the $\mathrm{Pb}$-treated group compared with the control group $(\mathrm{P}<0.05)$. GSPE alone did not increase CREA and BUN levels, but significantly $(\mathrm{P}<0.05)$ inhibited their increase induced by $\mathrm{Pb}$.

\section{GSPE ameliorates $\mathbf{P b}$-induced oxidative stress in the kidney}

We initially investigated specific indicators of oxidative stress, including the concentration of malondialdehyde (MDA) and glutathione (GSH), and the activity of superoxide dismutase (SOD) and glutathione S-transferase (GST). As expected, $\mathrm{Pb}$ administration for 5 weeks induced a significant increase in kidney MDA level compared with the control rats (Figure 2A, $\mathrm{P}<0.05)$. The coadministration of GSPE markedly attenuated the lipid peroxidation. The activities of SOD (Figure 2B) and GST (Figure 2C) in the kidney were significantly decreased in the $\mathrm{Pb}$-treated group ( $\mathrm{P}$ $<0.05$ ), and this effect was reversed significantly by GSPE treatment. In addition, we found that $\mathrm{Pb}$ treatment significantly reduced GSH level, however, GSPE prevented the decrease of GSH caused by $\mathrm{Pb}$ (Figure 2D, $\mathrm{P}<0.05)$.
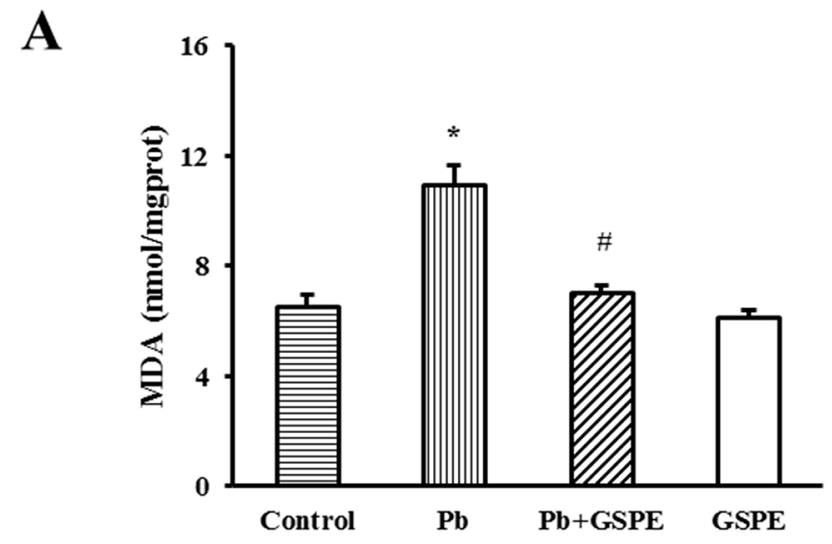

C

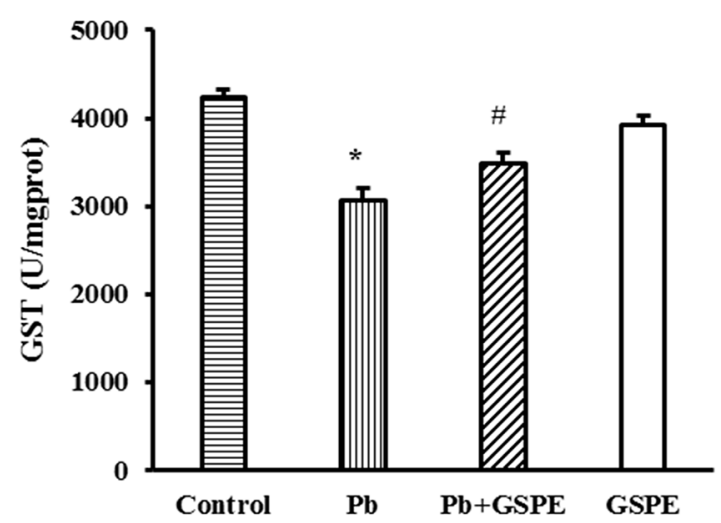

GSPE decreases total $\mathrm{Pb}$ concentrations in the kidney

To examine how GSPE prevents $\mathrm{Pb}$-induced renal toxicity, $\mathrm{Pb}$ retention in the kidney was measured (Figure 3). The total concentration of $\mathrm{Pb}$ in the $\mathrm{Pb}$-treated group was significantly higher than the control group $(\mathrm{P}<0.05)$. GSPE significantly attenuated $\mathrm{Pb}$ retention in the kidney $(\mathrm{P}<0.05)$.

\section{GSPE relieves renal inflammation}

As shown in Figure 4A, NF- $\kappa$ B and tumor necrosis factor- $\alpha$ (TNF- $\alpha$ ) protein levels were increased in the $\mathrm{Pb}$ treatment group. However, GSPE efficiently decreased $\mathrm{Pb}$ induced NF- $\kappa \mathrm{B}$ and TNF- $\alpha$ levels.

\section{GSPE ameliorates $\mathrm{Pb}$-induced nephrocyte apoptosis}

TUNEL staining was used to assess apoptosis in the kidney. As shown in Figure 5A and 5B, $\mathrm{Pb}$ exposure induced an obvious increase in TUNEL positive cells in renal areas compared with the control group. GSPE

B

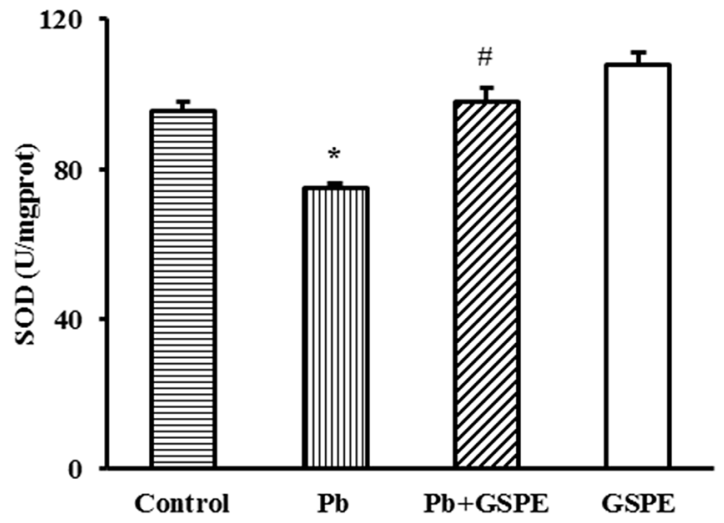

D

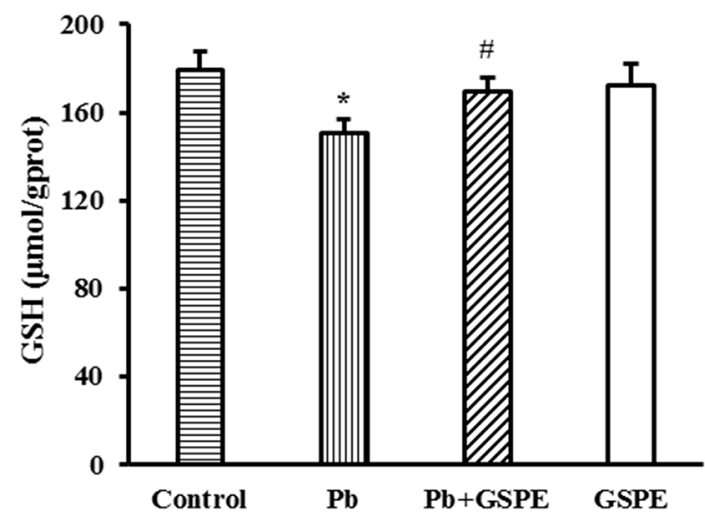

Figure 2: Effects of GSPE on oxidative stress indicators in Pb-treated rat kidneys. Samples were collected from control, $\mathrm{Pb}$-treated group, $\mathrm{Pb}+\mathrm{GSPE}$ group, and GSPE. A. The concentration of MDA in the kidney. $\mathbf{B}$. The activity of SOD in the kidney. C. The activity of GST in the kidney. D. The concentration of GSH in the kidney. Data are expressed as mean \pm SEM, $n=10{ }^{*}$ Significantly different $(\mathrm{P}<0.05)$ from control group, and ${ }^{*}$ significantly different $(\mathrm{P}<0.05)$ from $\mathrm{Pb}$-treated group. 
treatment with $\mathrm{Pb}$ exposure strongly decreased the rate of $\mathrm{Pb}$-induced renal cell death in the kidney.

To further establish the protective role of GSPE in $\mathrm{Pb}$-induced nephrocyte apoptosis, we measured the related apoptotic proteins Bax, P53, Bcl-2, and Bcl-xl. Our results showed that $\mathrm{Pb}$ increased the levels of $\mathrm{Bax}, \mathrm{P} 53$, and decreased the levels of Bcl-2 and Bcl-xl (Figure 5C and 5D). Notably, apoptosis in the kidney was inhibited by GSPE.

\section{GSPE inhibits the activation of GSK-3 $\beta$ induced} by $\mathbf{P b}$

GSK-3 $\beta$ is situated at the nexus of numerous signaling pathways. GSK-3 $\beta$ is inactivated on phosphorylation at Ser9. Therefore, we determined the phosphorylation status of GSK-3 $\beta$ at Ser9 residue by western blot analysis. Our results showed that $\mathrm{Pb}$ decreased the level of P-GSK-3 $\beta$ (Figure 6), and this was inhibited by GSPE.

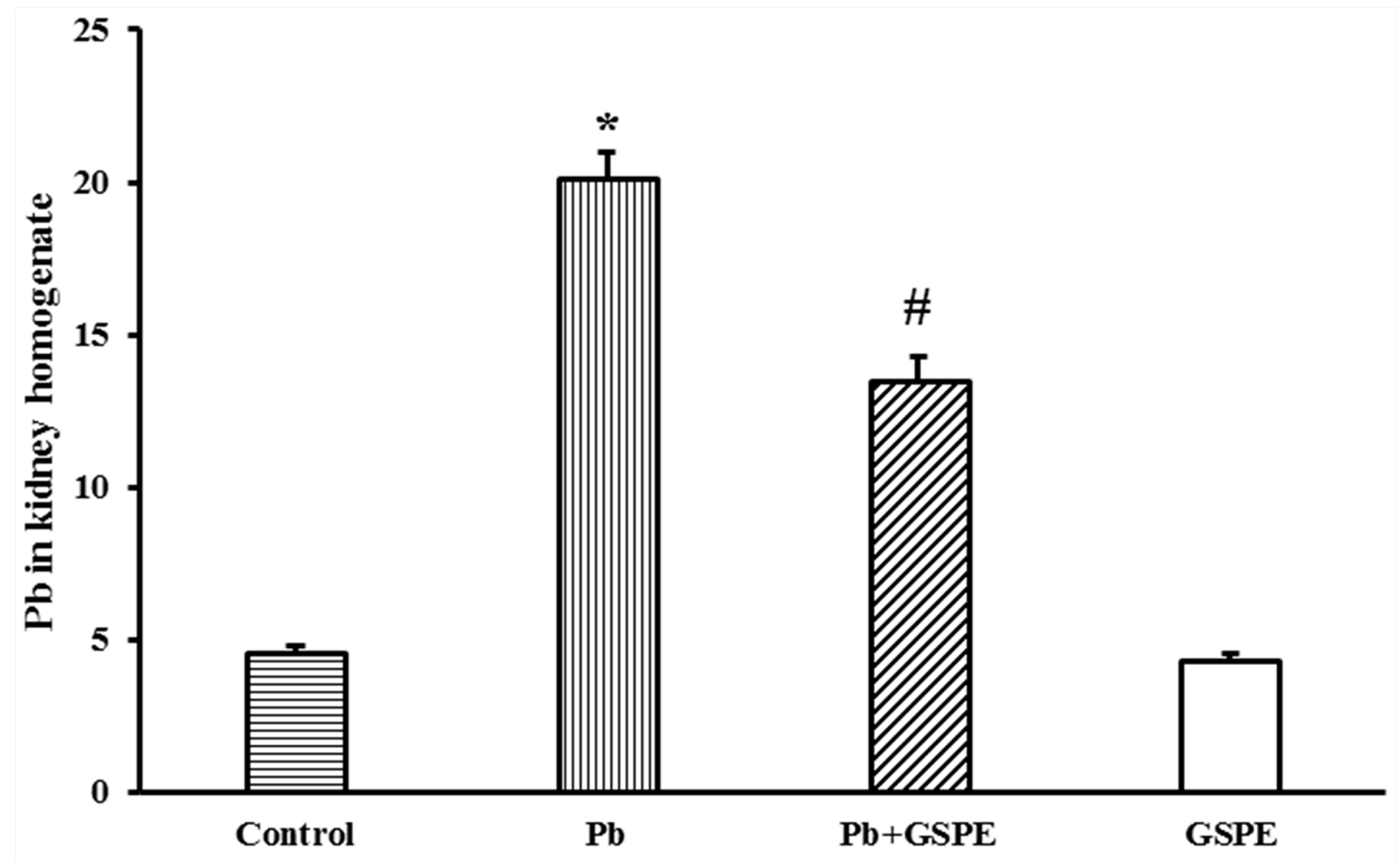

Figure 3: Total $\mathbf{P b}$ accumulation in rat kidney. Data are expressed as mean $\pm \mathrm{SEM}, \mathrm{n}=10 .{ }^{*}$ Significantly different $(\mathrm{P}<0.05)$ from control group, and ${ }^{\#}$ significantly different $(\mathrm{P}<0.05)$ from $\mathrm{Pb}$-treated group.

$\mathbf{A}$

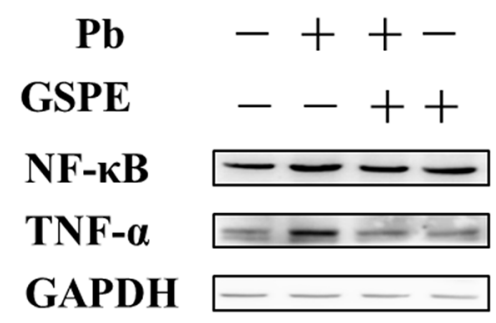

B

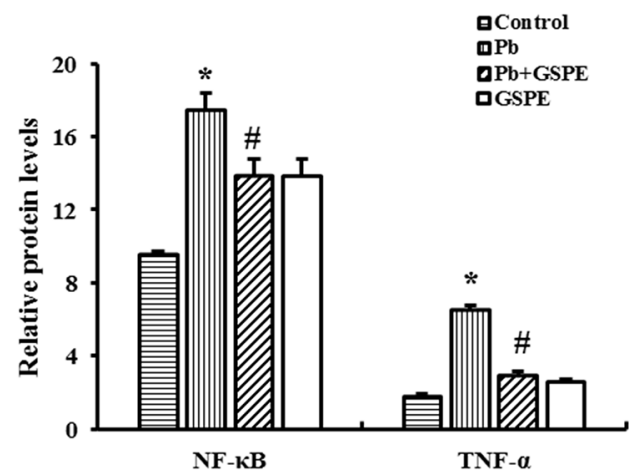

Figure 4: GSPE inhibited Pb-induced pro-inflammatory signals: the levels of NF- $\mathrm{B}$ and TNF- $\alpha$ in the kidney. A. The protein levels of NF- $\kappa$ B and TNF- $\alpha$. B. The values from densitometry of NF- $\kappa$ B and TNF- $\alpha$ were normalized to the level of GAPDH protein and expressed as fold increased. Data are expressed as mean \pm SEM of 4 independent experiments. *Significantly different $(\mathrm{P}<0.05)$ from control group, and "significantly different $(\mathrm{P}<0.05)$ from $\mathrm{Pb}$-treated group. 
A

Control
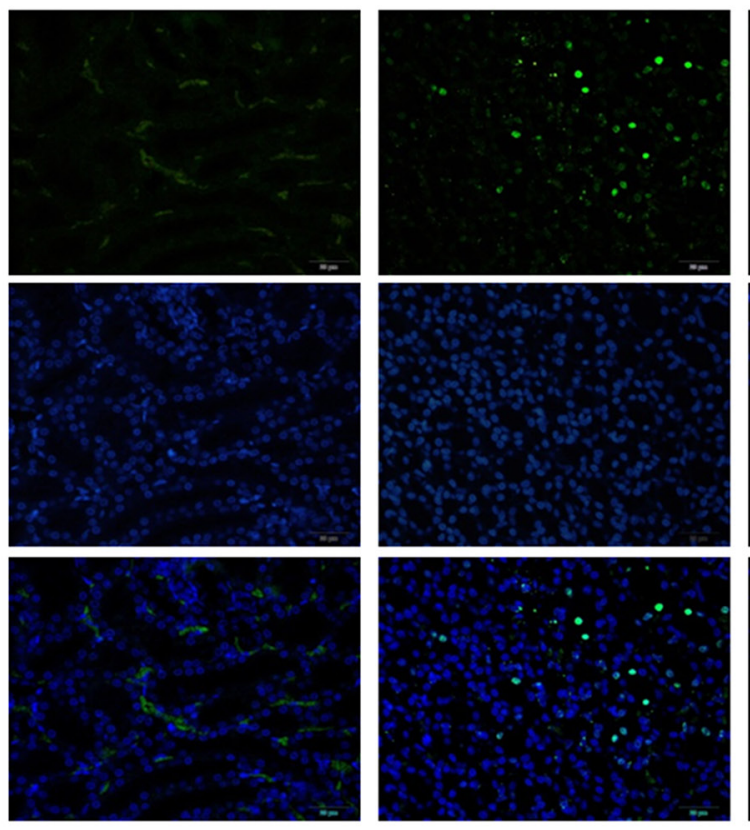

DAPI

Merge
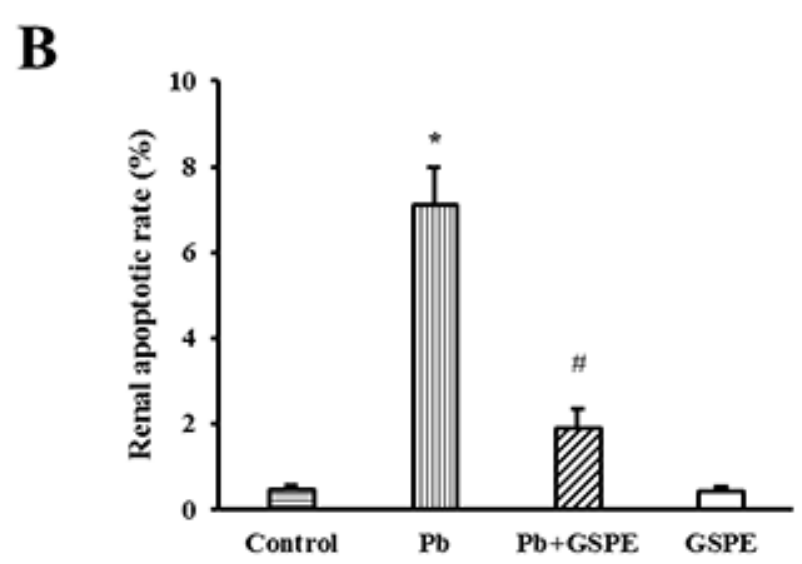

$\mathbf{C}$

D
Pb+GSPE
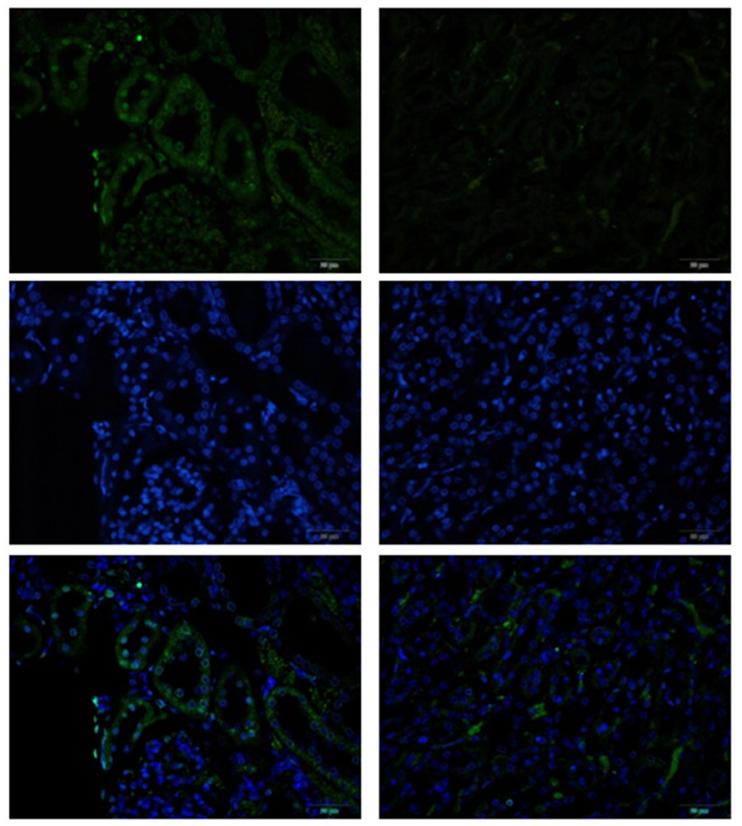
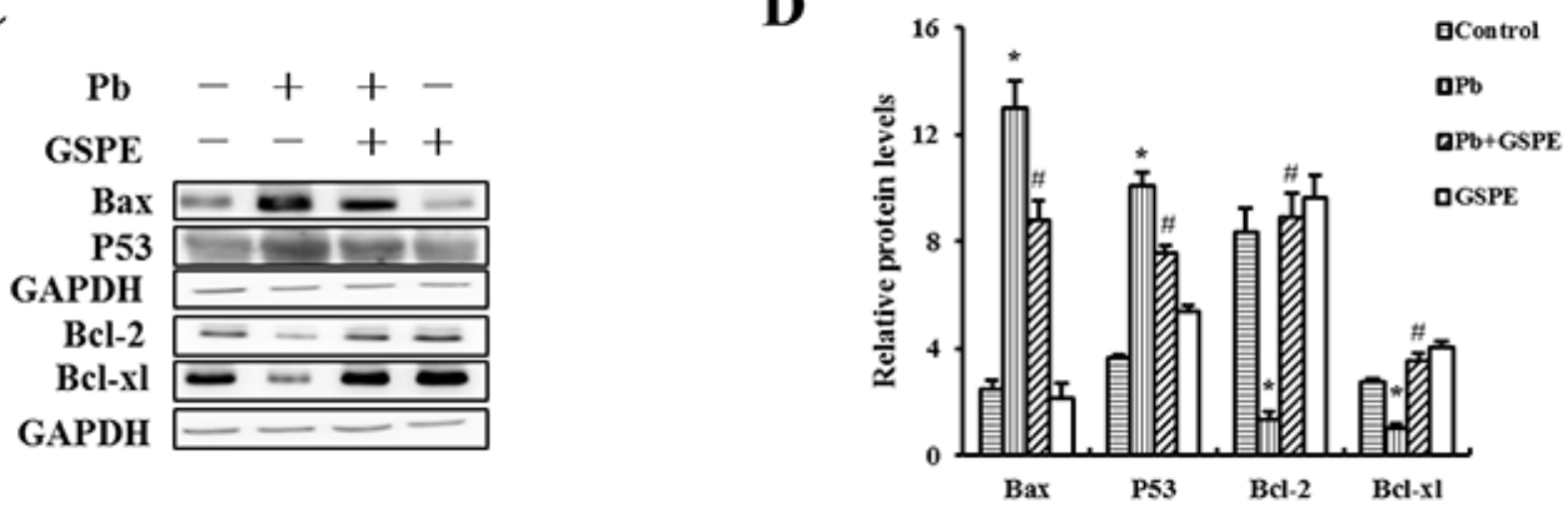

Figure 5: GSPE ameliorates Pb-induced nephrocyte apoptosis. A. Apoptosis was detected by in situ TUNEL (green) and DAPI (blue). B. Quantitative analysis of TUNEL-positive cells content. C. The protein levels of Bax, P53, Bcl-2, and Bcl-xl. D. The values from densitometry of Bax, P53, Bcl-2, and Bcl-xl were normalized to the level of GAPDH protein and expressed as fold increased. Data are expressed as mean \pm SEM of 4 independent experiments. ${ }^{*}$ Significantly different $(\mathrm{P}<0.05)$ from control group, and ${ }^{\#}$ significantly different $(\mathrm{P}<0.05)$ from $\mathrm{Pb}$-treated group. 


\section{GSPE activates the Nrf2 pathway in Pb-treated rat}

Nrf2 nuclear translocation is a necessary step of Nrf2 activation. First, we measured the protein levels of Nrf2 (nuclear and cytosolic), Kelch-like-ECH-associated protein 1 (Keap1), and Nrf2-target genes (NAD(P)H quinone oxidoreductase 1 (NQO1) and heme oxygenase-1 (HO-1)) (Figure 7A-7C). Next, relative quantitative real time RT-PCR analysis for miR153 was performed (Figure 7D). We found that $\mathrm{Pb}$ treatment decreased the levels of Nrf2, Keap1, NQO1, and HO-1, whereas miR153 expression was increased. However, these effects were reversed by GSPE.

\section{DISCUSSION}

Several studies have reported that $\mathrm{Pb}$ is nonbiodegradable, persists in the environment, and induces a variety of adverse effects over a long period. The chronic ingestion of $\mathrm{Pb}$ causes various well-documented pathologies in the kidney following its intestinal absorption and subsequent accumulation [20].

The serum levels of BUN and CREA can be interpreted as indices of renal dysfunction [21, 22]. Histopathological changes and the renal organ index are indicators used to evaluate the toxicity of $\mathrm{Pb}$ in rats [23]. In this study, histopathological changes, CREA and BUN levels, and renal organ index suggested that $\mathrm{Pb}$ caused kidney damage, while GSPE reversed it. Therefore, GSPE could be a useful therapeutic drug to inhibit the progression of $\mathrm{Pb}$-induced nephrotoxicity.

The excretion of $\mathrm{Pb}$ in the urine reflects a high concentration of $\mathrm{Pb}$ in the posterior kidney. Our results revealed that GSPE attenuated the specific bioaccumulation and retention of $\mathrm{Pb}$ in the kidney. Based on previous studies, $\mathrm{Pb}$ is incapable of inducing the production of metallothionein [24] and being a divalent cation, it is unlikely to be a permanent species. However, $\mathrm{Pb}$ has a negative impact on membrane structure and functionality, including lipid oxidation and membrane fluidity [25], which are partially responsible for $\mathrm{Pb}$ accumulation. Our studies showed that the level of MDA, an indicator of lipid peroxidation, were lower in the kidney of the GSPE $+\mathrm{Pb}$ group compared with the $\mathrm{Pb}$ group. Biochemical and biophysical findings suggest a detailed model of the composition and structure of membranes, which includes levels of dynamic organization both across the lipid bilayer (lipid asymmetry) and in the lateral dimension (lipid domains) of membranes [26]. Lipids play a crucial rule in the structure of cell membranes, suggesting that GSPE may plays a potential protective role in the cell membrane to inhibit the entry of $\mathrm{Pb}$ into cells.

MDA is one of the most important biomarkers in oxidative damage [27]. Antioxidant defense systems include enzymatic (SOD and GST) and nonenzymatic (GSH) antioxidant mechanisms [28]. Our results suggested that oxidative stress was involved in the pathophysiology of $\mathrm{Pb}$-induced renal injury. In the present study, increased MDA level, as well as decreased GSH concentration and activities of SOD and GST induced by $\mathrm{Pb}$ were consistently relieved by GSPE treatment. Thus, the antioxidant properties of GSPE appeared to underlie the mechanism of protective effects against kidney injury induced by $\mathrm{Pb}$.

A potential mechanism of excessive inflammation due to activation of NF- $\mathrm{KB}$ by oxidative stress supports the link between inflammation and oxidative stress in the progression of disease [29]. The transcription factor NF- $\kappa \mathrm{B}$ plays a critical role in the activation of down-
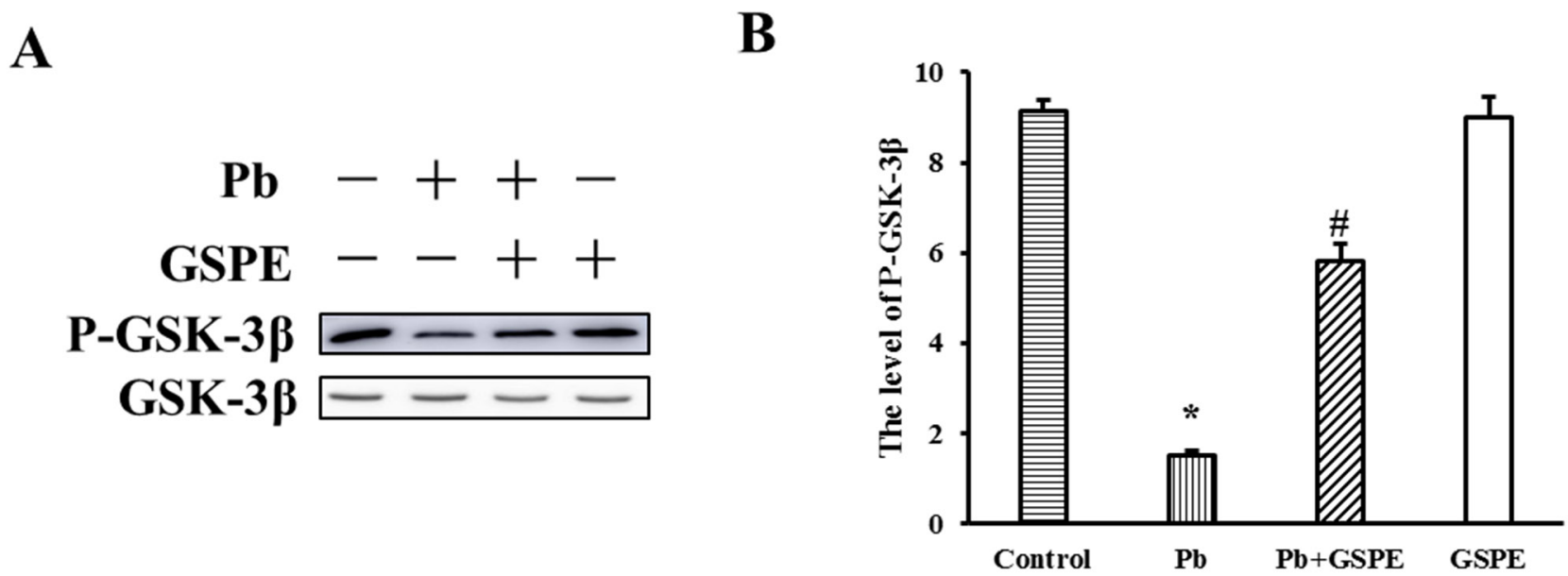

Figure 6: Effect of GSPE on the level of P-GSK-3 $\beta$ in Pb-induced nephrotoxicity. A. The protein levels of P-GSK-3 $\beta$ and GSK-3 $\beta$. B. The values from densitometry of P-GSK-3 $\beta$ were normalized to the level of GSK-3 $\beta$ protein and expressed as fold increased. Data are expressed as mean \pm SEM of 4 independent experiments. ${ }^{*}$ Significantly different $(\mathrm{P}<0.05)$ from control group, and ${ }^{\#}$ significantly different $(\mathrm{P}<0.05)$ from $\mathrm{Pb}$-treated group. 
A

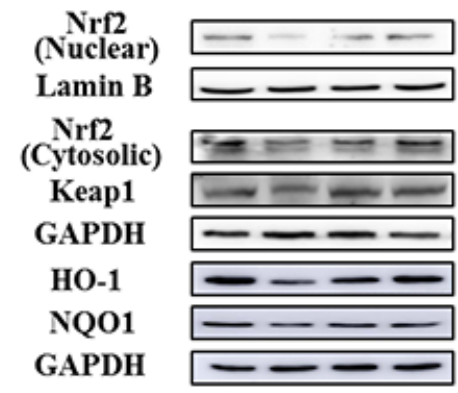

C

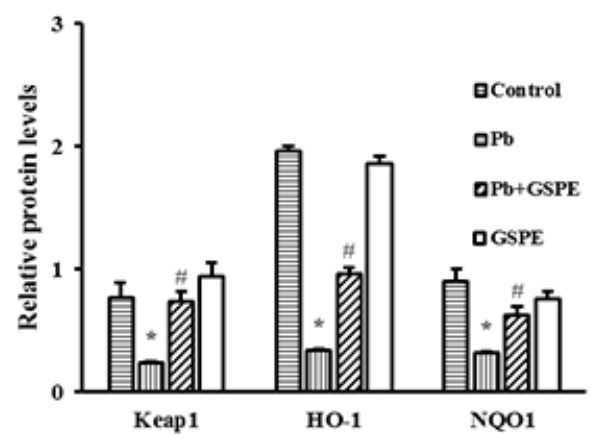

B

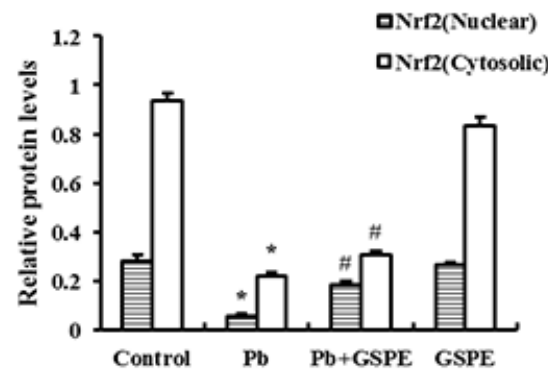

D

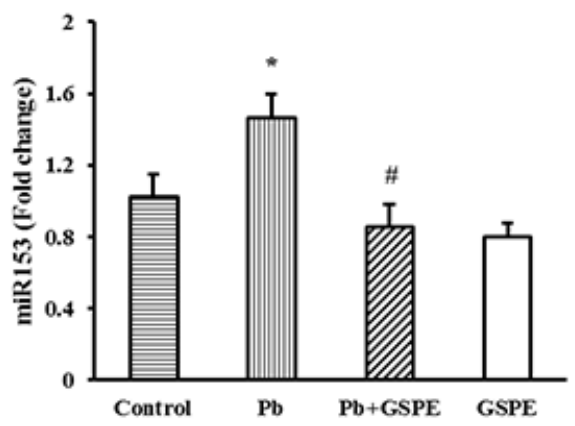

Figure 7: Effects of GSPE on the levels of Nrf2, Keap1, NQO1, HO-1 and miR153 in Pb-treated kidney. A. The protein levels of Nrf2 (nuclear and cytosolic), Keap1, NQO1, and HO-1. B. The values from densitometry of Nrf2 (nuclear) are normalized to the level of Lamin B protein and expressed as fold increased. B-C. The values from densitometry of Nrf2 (cytosolic), Keap1, NQO1, and HO-1 are normalized to the level of GAPDH protein and expressed as fold increased. D. Quantification of the level of miR153. Data are expressed as mean \pm SEM of 4 independent experiments. miRNA expression is shown as fold change with respect to control group. * Significantly different $(\mathrm{P}<0.05)$ from control group, and ${ }^{\#}$ significantly different $(\mathrm{P}<0.05)$ from $\mathrm{Pb}$-treated group.

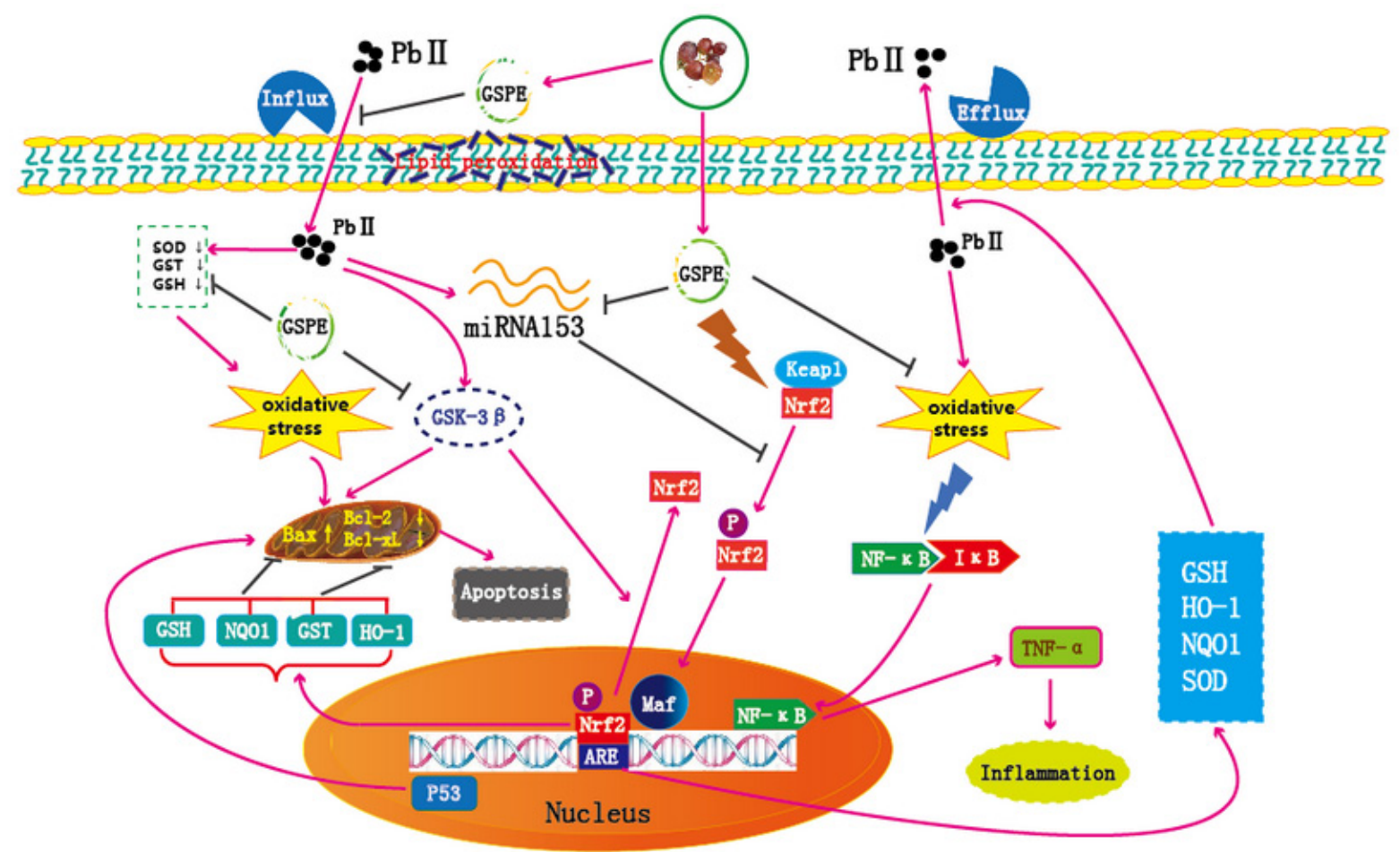

Figure 8: Schematic diagram of the protective mechanism for GSPE in Pb-induced nephrotoxicity. Peachblow line denotes stimulation, brown line denotes inhibition, " " denotes dissociation. 
stream genes responsible for secreting pro-inflammatory cytokines, so that it mediates many pro-inflammatory and cell death pathways [30]. TNF- $\alpha$, a pro-inflammatory cytokine, which can stimulate fibroblasts, endothelial cells, and macrophages to produce chemokines, resulted in tissue damage and chronic inflammation [31]. Our results showed that $\mathrm{Pb}$ exposure resulted in intracellular superoxide production, whereas GSPE efficiently suppressed MDA, which was accompanied by the down regulation of NF- $\mathrm{\kappa B}$ and TNF- $\alpha$. In this study, Pb exerted an effect in renal tissues by oxidative stress, and the subsequent NF- $\mathrm{\kappa B}$ activation resulted in inflammatory. Our results demonstrate that GSPE exerts a significant suppressive effect on inflammatory induced by $\mathrm{Pb}$.

Oxidative stress is a known promoter of apoptosis, the release of inflammatory cytokines and mediators are associated with the pathogenesis of $\mathrm{Pb}$ induced apoptosis [32]. P53 activation triggers apoptosis through activating pro-apoptotic proteins [33]. Based on our results, P53-dependent cell death was involved in $\mathrm{Pb}$-induced nephrotoxicity, which leading to the activation of Bax. Bax harbors a highly conserved domain, which promotes the progress of apoptosis by directly inducing cytochrome $\mathrm{c}$ release from mitochondria or suppressing anti-apoptotic activity by forming Bax-Bcl-2 heterodimers [34]. Our data showed that the modulation of pro-apoptotic and anti-apoptotic protein expression in rat kidney after $\mathrm{Pb}$ treatment was reversed by GSPE, revealing the antiapoptotic effect of this compound in $\mathrm{Pb}$-induced kidney injury. A direct link between Nrf2 and both Bcl-2 and Bcl$\mathrm{xl}$ expression was previously shown, because these two anti-apoptotic proteins are under transcriptional control by Nrf2, which binds to antioxidant response element (ARE) located in the promoter region of the corresponding genes [35]. A possible explanation is that GSPE protects renal cells against apoptosis induced by $\mathrm{Pb}$ via activating the Nrf2 pathway.

Nrf2 accumulates and translocates to the nucleus where it heterodimerizes with small Maf or other uncertain nuclear proteins, binds to ARE, and finally activates the downstream genes [36]. In the present study, GSPE increased the content of Nrf2 in nucleus, as well as reversed the $\mathrm{Pb}$-induced decrease of the levels of HO-1 and NQO1, the activity of GST, and the concentration of GSH, which are downstream targets of Nrf2. Thus, GSPE plays a critical role in the activation of Nrf2, which attenuates $\mathrm{Pb}$-induced nephrotoxicity by antioxidant, anti-apoptosis, and detoxification mechanisms. Keap1 is in the off position and functions as an E3 ubiquitin ligase, constantly targeting $\mathrm{Nrf} 2$ with Cul3-Rbx1 for ubiquitination and proteasomal degradation [37]. However, in this study, administration of GSPE increased Keap1 level in Pb-treated rat kidney, so GSPE may activate Nrf2 pathway in Keap1-independent manner.

miRNAs are small segments of noncoding RNA that regulate gene expression and protein function, and therefore are key regulators of diseases [38]. Nrf2 pathway was found to be negatively regulated by miRNAs. It was reported that miR153 suppressed Nrf2 gene expression through 3' untranslated region binding and down-modulating Nrf2 mRNA [39]. In this study, higher expression of miR153 and decreased Nrf2 level have been observed in the kidney of rats treated by $\mathrm{Pb}$, GSPE reversed the increase of miR153 induced by $\mathrm{Pb}$ as expected. Thus, GSPE activate Nrf2 pathway at least partially through inhibiting miR153.

Suppression of proteasomal degradation of $\mathrm{Nrf} 2$ could activate Nrf2 pathway [40]. GSK-3 $\beta$ phosphorylates $\mathrm{Nrf2}$, leading to exclusion of Nrf2 from the nucleus and promoting Nrf2 ubiquitination [36, 41]. It has been reported that $\mathrm{N}$-terminal region of Nrf2 initiates rapid proteolysis within the cytoplasm, but mediates turnover via a slower pathway in the nucleus [42]. Here, the result showed that $\mathrm{Pb}$ stress in rat renal tissues significantly decreased the level of p-GSK-3 $\beta$. The activity of GSK$3 \beta$ can be inhibited by phosphorylation. Therefore, GSK$3 \beta$ mediates the nephrotoxicity of $\mathrm{Pb}$ via inhibiting $\mathrm{Nrf} 2$ pathway. Surprisingly, GSPE promoted phosphorylation of GSK-3 $\beta$, indicating it might be an effective inhibitor of GSK-3 $\beta$. Accordingly, GSPE suppresses proteolytic degradation of Nrf2 induced by $\mathrm{Pb}$ via inhibiting the activity of GSK-3 $\beta$, thereby increasing Nrf2 nuclear translocation.

In summary, $\mathrm{Pb}$-induced oxidative stress in rat kidneys was attenuated by GSPE treatment via activating the Nrf2 signaling pathway involved in suppression of miR153 and GSK-3 $\beta$ (Figure 8). Nrf2 signaling provides a new therapeutic target for renal injury induced by $\mathrm{Pb}$, and GSPE could be a potential natural agent to protect against $\mathrm{Pb}$-induced nephrotoxicity.

\section{MATERIALS AND METHODS}

\section{Animals and treatment}

All animal procedures were conducted in accordance with the guidelines of the Ethical Committee for Animal Experiments (Northeast Agricultural University, Harbin, China). Healthy male albino Wistar rats (6 to 8 weeks of age, with average body weight of $110 \pm 10 \mathrm{~g}$ ) were used in this study. The animals were acclimated for 7 days under the same laboratory conditions with a 12-h interval light/ dark cycle, a minimum of $40 \%$ relative humidity, and a room temperature of $21 \pm 4^{\circ} \mathrm{C}$. Food (standard diet) and water were available and libitum. The rats were randomly divided into 4 groups of 10 animals each and were treated for 5 weeks as follows: control, $\mathrm{Pb}$-treated, $\mathrm{Pb}+\mathrm{GSPE}$, and GSPE. The control group received tap water and was given $0.9 \%$ physiological saline by intragastric administration. The $\mathrm{Pb}$ group received an aqueous solution containing 2,500 ppm of $\mathrm{Pb}$ acetate $(0.25 \%, \mathrm{w} / \mathrm{v})$ and was given $0.9 \%$ physiological saline. The $\mathrm{Pb}+\mathrm{GSPE}$ group 
was cotreated with $\mathrm{Pb}$ (as in $\mathrm{Pb}$ group) plus GSPE (200 $\mathrm{mg} / \mathrm{kg}$, gastric gavage). The GSPE group received tap water and was given GSPE (200 mg/kg) by intragastric administration. Lead acetate was purchased from the Benchmark Chemical Reagent co., Ltd (Tianjin, China). Grape seed procyanidin was obtained from the Niulan Biological Products co., Ltd (Changsha, China). At the end of the treatment period, the animals were weighed and anesthetized with ether.

\section{Biochemical analysis}

Blood samples were collected from the jugular vein into evacuated tubes that contained heparin sodium as an anticoagulant. The samples were centrifuged at 3,000 rpm for $10 \mathrm{~min}$ within $1 \mathrm{~h}$ after collection. Serum samples were collected to determine the CREA and BUN levels using UniCel DxC800 Synchron (Bekman, USA). Renal tissues were rapidly excised and weighted then homogenized in phosphate-buffered saline $(\mathrm{PH} 7.4, \mathrm{w} / \mathrm{v} ; 1 \mathrm{~g}$ tissue with $9 \mathrm{ml}$ PBS) with an Ultra-Turrax T25 Homogenizer. After centrifugation at 3,500 rpm for $10 \mathrm{~min}$ at $4^{\circ} \mathrm{C}$. The supernatant was used to determine the MDA and GSH concentration levels and activities of the antioxidant enzymes (i., SOD, GST), which were measured using assay kits from Nanjing Jiancheng Bioengineering Institute (Nanjing, China) according to the manufacturer's instructions.

\section{Histopathological analysis}

The $10 \%$ neutral-buffered formalin solutionfixed kidneys were embedded in paraffin; sections with a thickness of 5-6 $\mu \mathrm{m}$ were sliced from the paraffinembedded blocks and stained with hematoxylin and eosin stain. Then, the histological slides were examined by light microscopy (BX-FM; Olympus Corp, Tokyo, Japan).

\section{Total $\mathrm{Pb}$ analysis in the kidney}

Briefly, approximately $0.5 \mathrm{~g}$ renal tissues were ashed at $500^{\circ} \mathrm{C}$ for $16 \mathrm{~h}$. Ashed samples were digested by heating to a slow boil in a very small amount of perchloric acid and nitric acid over 4-6 h. $10 \mathrm{ml}$ of hydrochloric acid were added, and water was added to concentrated samples $(50 \mathrm{ml})$. Absorbance readings were performed with a 930 System Atomic Fluorescence Spectrometer.

\section{TUNEL assay}

The detection of apoptosis was performed with a TUNEL detection kit (Kaiji, Nanjing, China). The procedure was conducted according to the manufacturer's instructions. Sections $(4 \mu \mathrm{m})$ from the paraffin-embedded blocks were dewaxed and added non DNase protease K. Nest sections were rinsed 3 times with PBS, labeled at $37^{\circ} \mathrm{C}$ for $60 \mathrm{~min}$ with the TUNEL reaction mixture, and rinsed again with PBS. The number of apoptotic cell was counted from 10 to 20 random fields $(200 \times)$ of a coverslip. Cells were examined and recorded under a fluorescence microscopy.

\section{Western bolt analysis}

Total protein of kidney tissues was lysed in RIPA buffer supplement with the protease inhibitor PMSF (Beyotime, Shanghai, China). Briefly, the homogenate was centrifuged at $12,000 \mathrm{rpm}$ for $10 \mathrm{~min}$ at $4^{\circ} \mathrm{C}$ and supernatant was collected. Nuclear and cytosolic proteins were extracted using a Nuclear and Cytoplasmic Protein Extraction Kit (Beyotime) following the manufacturer's instruction. Total protein content was determined using BCA protein assay kit (Beyotime). Equal amounts of sample $(10 \mu 1,3 \mathrm{mg} / \mathrm{ml})$ were loaded on SDS-PAGE and transferred to PVDF membranes. After blockage of nonspecific binding sites with $5 \%$ nonfat milk in TBST (TBS and $20 \%$ Tween 20) for $2 \mathrm{~h}$ at room temperature, membranes were incubated overnight at $4^{\circ} \mathrm{C}$ with diluted Primary antibodies against-Bax, Bcl-2, Bcl-xl, P53,

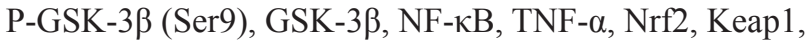
NQO1, and HO-1, respectively. Above primary antibodies against each protein were from Santa Cruz Biotechnology (Santa Cruz, CA, USA). Nuclear protein Lamin B (Santa Cruz, CA, USA) and GAPDH (Xianzhi, Hangzhou, China) were used as loading controls. The membranes were then washed 4 times with TBST, incubated further with the appropriate horseradish peroxide conjugated secondary antibody at $37^{\circ} \mathrm{C}$ for $45 \mathrm{~min}$, and then washed 5 times with TBST. Subsequently, bands quantified using Image Pro-Plus 6.0 software (General Electric Company, Fairfield, CT, USA).

\section{miR153 isolation and relative quantitative real- time PCR analysis}

miR153 was extracted using SanPrep Column miRNA Mini-Preps Kit (Sangon Biotech, Shanghai, China) according to the manufacturer's instructions. For real time PCR analysis of miR153, cDNA was used. miRNA detection by real time analysis involved reverse transcription of cDNA using a small RNA specific stemloop RT primer (5'-CTCAACTGGTGTCGTGGAGTCGG CAATTCAGTTGAGGATCACT-3'). The thermal cycling included 3 min of denaturation at $95^{\circ} \mathrm{C}$ followed by 45 PCR cycles, including $15 \mathrm{~s}$ at $95^{\circ} \mathrm{C}, 20 \mathrm{~s}$ at $57^{\circ} \mathrm{C}$, and 30 $\mathrm{s}$ at $72^{\circ} \mathrm{C}$. The comparative $\mathrm{Ct}\left(2^{-\Delta \Delta \mathrm{Ct}}\right)$ method was used to analyze the relative expression of miR153, which were normalized to U6.

\section{Statistical analysis}

Statistical analyses were performed using SPSS 19.0 software (SPSS, Chicago, IL, USA). All datas are expressed as mean \pm SEM. Statistical analysis was 
performed by one-way ANOVA (analysis of variance) and using Tukey's post hoc test to assess significance. Values with $\mathrm{P}<0.05$ were considered as statistically significant.

\section{Abbreviations}

BUN: blood urea nitrogen; CREA: creatinine; GSH: glutathione; GSK-3 $\beta$ : glycogen synthase kinase $3 \beta$; GSPE: grape seed procyanidin extract; GST: glutathione S-transferase; HO-1: heme oxygenase-1; MDA:

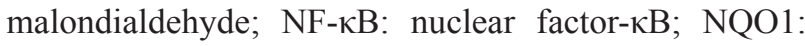
$\mathrm{NAD}(\mathrm{P}) \mathrm{H}$ quinone oxidoreductase 1 ; Nrf2: nuclear factorerythroid-2-related factor 2; $\mathrm{Pb}$ : lead; SOD: superoxide dismutase; TNF- $\alpha$ : tumor necrosis factor- $\alpha$

\section{Author contributions}

B.L. and Z.Z. designed and conducted experiments, and wrote the manuscript. H.Z. carried out animal experiments. X.T. completed the determination of MDA and GSH. D.Y. and Z.L. participated in haematoxylin eosin staining. H.J. and J.L. finished TUNEL assay. R.B. performed the statistical analyses. All the authors contributed to and approved the final manuscript.

\section{CONFLICTS OF INTEREST} interest.

The authors declare that they have no conflict of

\section{FUNDING}

This work was funded by the National Science Foundation Committee of China (31101868), Program for New Century Excellent Talent in Heilongjiang Provincial University (1253-NCET-007), Scientific Research Foundation for Excellent Returned Scholars of Heilongjiang Province, University Nursing Program for Young Scholar with Creative Talents in Heilongjiang Province (UNPYSCT-2016012), and Academic Backbone Support Program (15XG17) to ZG Zhang approved by Northeast Agricultural University.

\section{REFERENCES}

1. Tian Y, Green PG, Stamova B, Hertz-Picciotto I, Pessah IN, Hansen R, Yang X, Gregg JP, Ashwood P, Jickling G, Van de Water J, Sharp FR. Correlations of gene expression with blood lead levels in children with autism compared to typically developing controls. Neurotox Res. 2011; 19:1-13.

2. Winiarska-Mieczan A, Kwiecien M. The effect of exposure to $\mathrm{Cd}$ and $\mathrm{Pb}$ in the form of a drinking water or feed on the accumulation and distribution of these metals in the organs of growing Wistar Rats. Biol Trace Elem Res. 2016; 169:230-236.
3. Reyes JL, Molina-Jijón E, Rodríguez-Muñoz R, Bautista-García P, Debray-García Y, Namorado Mdel C. Tight junction proteins and oxidative stress in heavy metals-induced nephrotoxicity. Biomed Res Int. 2013; 2013:730789.

4. Abdel-Moneim AM, El-Toweissy MY, Ali AM, Awad Allah AA, Darwish HS, Sadek IA. Curcumin ameliorates lead $\left(\mathrm{Pb}^{2+}\right)$-induced hemato-biochemical alterations and renal oxidative damage in a rat model. Biol Trace Elem Res. 2015; 168:206-220

5. Nair AR, Lee WK, Smeets K, Swennen Q, Sanchez A, Thévenod F, Cuypers A. Glutathione and mitochondria determine acute defense responses and adaptive processes in cadmium-induced oxidative stress and toxicity of the kidney. Arch Toxicol. 2015; 89:2273-2289.

6. Gong $\mathrm{X}$, Ivanov VN, Davidson MM, Hei TK. Tetramethylpyrazine (TMP) protects against sodium arsenite-induced nephrotoxicity by suppressing ROS production, mitochondrial dysfunction, pro-inflammatory signaling pathways and programed cell death. Arch Toxicol. 2015; 89:1057-1070.

7. Bonizzi G, Karin M. The two NF-кB activation pathways and their role in innate and adaptive immunity. Trends Immunol. 2004; 25:280-288.

8. Liu CM, Sun YZ, Sun JM, Ma JQ, Cheng C. Protective role of quercetin against lead-induced inflammatory response in rat kidney through the ROS-mediated MAPKs and NF- $\mathrm{BB}$ pathway. Biochim Biophys Acta. 2012; 1820:1693-1703.

9. Zheng J, Zhao T, Yuan Y, Hu N, Tang X. Hydrogen sulfide $\left(\mathrm{H}_{2} \mathrm{~S}\right)$ attenuates uranium-induced acute nephrotoxicity through oxidative stress and inflammatory response via Nrf2-NF- $\kappa$ B pathways. Chem Biol Interact. 2015; 242:353-362.

10. Li C, Ge Y, Peng A, Gong R. The redox sensitive glycogen synthase kinase $3 \beta$ suppresses the selfprotective antioxidant response in podocytes upon oxidative glomerular injury. Oncotarget. 2015; 6:3949339506. doi: 10.18632/oncotarget.6303.

11. Kaspar JW, Niture SK, Jaiswal AK. Nrf2:INrf2 (Keap1) signaling in oxidative stress. Free Radic Biol Med. 2009; 47:1304-1309.

12. Narasimhan M, Riar AK, Rathinam ML, Vedpathak D, Henderson G, Mahimainathan L. Hydrogen peroxide responsive miR153 targets Nrf2/ARE cytoprotection in paraquat induced dopaminergic neurotoxicity. Toxicol Lett. 2014; 228:179-191.

13. Flora SJ, Pachauri V. Chelation in metal intoxication. Int $\mathbf{J}$ Environ Res Public Health. 2010; 7:2745-2788.

14. Nazima B, Manoharan V, Miltonprabu S. Grape seed proanthocyanidins ameliorates cadmium-induced renal injury and oxidative stress in experimental rats through the up-regulation of nuclear related factor 2 and antioxidant responsive elements. Biochem Cell Biol. 2015; 93:210-226. 
15. Gao Z, Liu G, Hu Z, Li X, Yang X, Jiang B, Li X. Grape seed proanthocyanidin extract protects from cisplatininduced nephrotoxicity by inhibiting endoplasmic reticulum stress-induced apoptosis. Mol Med Rep. 2014; 9:801-807.

16. Ulusoy S, Ozkan G, Mungan S, Orem A, Yulug E, Alkanat $\mathrm{M}$, Yucesan FB. GSPE is superior to NAC in the prevention of contrast-induced nephropathy: might this superiority be related to caspase 1 and calpain 1? Life Sci. 2014; 103:101-110.

17. Hassan HA, Edrees GM, El-Gamel EM, El-Sayed EA. Amelioration of cisplatin-induced nephrotoxicity by grape seed extract and fish oil is mediated by lowering oxidative stress and DNA damage. Cytotechnology. 2014; 66:419-429.

18. Ozkan G, Ulusoy S, Orem A, Alkanat M, Mungan S, Yulug E, Yucesan FB. How does colistin-induced nephropathy develop and can it be treated? Antimicrob Agents Chemother. 2013; 57:3463-3469.

19. Ulusoy S, Ozkan G, Yucesan FB, Ersöz Ş, Orem A, Alkanat M, Yuluğ E, Kaynar K, Al S. Anti-apoptotic and anti-oxidant effects of grape seed proanthocyanidin extract in preventing cyclosporine A-induced nephropathy. Nephrology (Carlton). 2012; 17:372-379.

20. Breton J, Le Clère K, Daniel C, Sauty M, Nakab L, Chassat T, Dewulf J, Penet S, Carnoy C, Thomas P, Pot B, Nesslany F, Foligné B. Chronic ingestion of cadmium and lead alters the bioavailability of essential and heavy metals, gene expression pathways and genotoxicity in mouse intestine. Arch Toxicol. 2013; 87:1787-1795.

21. Lin L, Cui F, Zhang J, Gao X, Zhou M, Xu N, Zhao H, Liu M, Zhang C, Jia L. Antioxidative and renoprotective effects of residue polysaccharides from Flammulina velutipes. Carbohydr Polym. 2016; 146:388-395.

22. Yu M, Xue J, Li Y, Zhang W, Ma D, Liu L, Zhang Z. Resveratrol protects against arsenic trioxide-induced nephrotoxicity by facilitating arsenic metabolism and decreasing oxidative stress. Arch Toxicol. 2013; 87:1025-1035.

23. Ahmad M, Lim CP, Akowuah GA, Ismail NN, Hashim MA, Hor SY, Ang LF, Yam MF. Safety assessment of standardised methanol extract of Cinnamomum burmannii. Phytomedicine. 2013; 20:1124-1130.

24. Dai W, Fu L, Du H, Liu H, Xu Z. Effects of montmorillonite on $\mathrm{Pb}$ accumulation, oxidative stress, and DNA damage in Tilapia (Oreochromis niloticus) exposed to dietary $\mathrm{Pb}$. Biol Trace Elem Res. 2010; 136:71-78.

25. Verstraeten SV, Aimo L, Oteiza PI. Aluminium and lead: molecular mechanisms of brain toxicity. Arch Toxicol. 2008; 82:789-802.

26. Pera H, Kleijn JM, Leermakers FA. Linking lipid architecture to bilayer structure and mechanics using selfconsistent field modelling. J Chem Phys. 2014; 140:065102.

27. Zhang J, Cao H, Zhang Y, Zhang Y, Ma J, Wang J, Gao Y, Zhang X, Zhang F, Chu L. Nephroprotective effect of calcium channel blockers against toxicity of lead exposure in mice. Toxicol Lett. 2013; 218:273-280.

28. Zhang W, Xue J, Ge M, Yu M, Liu L, Zhang Z. Resveratrol attenuates hepatotoxicity of rats exposed to arsenic trioxide. Food Chem Toxicol. 2012; 51:87-92.

29. Turillazzi E, Neri M, Cerretani D, Cantatore S, Frati P, Moltoni L, Busardò FP, Pomara C, Riezzo I, Fineschi V. Lipid peroxidation and apoptotic response in rat brain areas induced by long-term administration of nandrolone: the mutua 1 crosstalk between ROS and NF-kB. J Cell Mol Med. 2016; 20:601-612.

30. Kaulmann A, Legay S, Schneider YJ, Hoffmann L, Bohn T. Inflammation related responses of intestinal cells to plum and cabbage digesta with differential carotenoid and polyphenol profiles following simulated gastrointestinal digestion. Mol Nutr Food Res. 2016; 60:992-1005.

31. Shanmugam G, Narasimhan M, Sakthivel R, Kumar RR, Davidson C, Palaniappan S, Claycomb WW, Hoidal JR, Darley-Usmar VM, Rajasekaran NS. A biphasic effect of TNF- $\alpha$ in regulation of the Keap1/Nrf2 pathway in cardiomyocytes. Redox Biol. 2016; 9:77-89.

32. Malik S, Suchal K, Bhatia J, Khan SI, Vasisth S, Tomar A, Goyal S, Kumar R, Arya DS, Ojha SK. Therapeutic potential and molecular mechanisms of emblica officinalis gaertn in countering nephrotoxicity in rats induced by the chemotherapeutic agent cisplatin. Front Pharmacol. 2016; 7:350.

33. Jin $\mathrm{H}$, Yin $\mathrm{S}$, Song $\mathrm{X}$, Zhang E, Fan L, Hu H. p53 activation contributes to patulin-induced nephrotoxicity via modulation of reactive oxygen species generation. Sci Rep. 2016; 6:24455.

34. Luo SW, Wang WN, Sun ZM, Xie FX, Kong JR, Liu $\mathrm{Y}$, Cheng $\mathrm{CH}$. Molecular cloning, characterization and expression analysis of (B-cell lymphoma-2 associated X protein) Bax in the orange-spotted grouper (Epinephelus coioides) after the Vibrio alginolyticus challenge. Dev Comp Immunol. 2016; 60:66-79.

35. Ariza J, González-Reyes JA, Jódar L, Díaz-Ruiz A, de Cabo R, Villalba JM. Mitochondrial permeabilization without caspase activation mediates the increase of basal apoptosis in cells lacking Nrf2. Free Radic Biol Med. 2016; 95:82-95.

36. Mathur A, Rizvi F, Kakkar P. PHLPP2 down regulation influences nuclear Nrf2 stability via Akt-1/Gsk3ß/Fyn kinase axis in acetaminophen induced oxidative renal toxicity: protection accorded by morin. Food Chem Toxicol. 2016; 89:19-31.

37. Bryan HK, Olayanju A, Goldring CE, Park BK. The Nrf2 cell defence pathway: Keap1-dependent and -independent mechanisms of regulation. Biochem Pharmacol. 2013; 85:705-717.

38. Weaver JL, Matheson PJ, Hurt RT, Downard CD, McClain CJ, Garrison RN, Smith JW. Direct peritoneal resuscitation alters hepatic mirna expression after hemorrhagic shock. J Am Coll Surg. 2016; 223:68-75. 
39. Narasimhan M, Patel D, Vedpathak D, Rathinam M, Henderson G, Mahimainathan L. Identification of novel microRNAs in post-transcriptional control of $\mathrm{Nrf} 2$ expression and redox homeostasis in neuronal, SH-SY5Y cells. PLoS One. 2012; 7:e51111.

40. Bhakkiyalakshmi E, Sireesh D, Rajaguru P, Paulmurugan $\mathrm{R}$, Ramkumar KM. The emerging role of redox-sensitive Nrf2-Keap1 pathway in diabetes. Pharmacol Res. 2015; 91:104-114.
41. Mittal SP, Khole S, Jagadish N, Ghosh D, Gadgil V, Sinkar $\mathrm{V}$, Ghaskadbi SS. Andrographolide protects liver cells from $\mathrm{H}_{2} \mathrm{O}_{2}$ induced cell death by upregulation of Nrf-2/HO-1 mediated via adenosine $\mathrm{A}_{2 \mathrm{a}}$ receptor signaling. Biochim Biophys Acta. 2016; 1860:2377-2390.

42. Itoh K, Wakabayashi N, Katoh Y, Ishii T, O'Connor T, Yamamoto M. Keap1 regulates both cytoplasmic-nuclear shuttling, degradation of Nrf2 in response to electrophiles. Genes Cells. 2003; 8:379-391. 